\title{
GEOGRAFÍA MÉDICA DE CASO (ASTURIAS) (1945)
}

\author{
Francisco Feo Parrondo ${ }^{1}$ \\ Universidad Autónoma de Madrid
}

\section{RESUMEN}

La Geografía médica de Caso (1945) analiza de forma pormenorizada la situación demográfica y sanitaria de este municipio, la influencia de los factores físicos y humanos para concluir con una revisión somera de las principales enfermedades que afectaban a los habitantes.

Palabras clave: Geografía médica, sociedad, economía, población, epidemias.

\section{MEDICAL GEOGRAPHY OF CASO (ASTURIAS) (1945)}

\section{ABSTRACT}

The Medical Geography of Caso (Asturias) (1945) analyses in a precise way the demographic and sanitary situation of this district, the influence of physical and human factors. Finally there have been examined the main diseases affecting its in habitants at that time.

Key words: Medical Geography, society, economy, population, epidemics.

\section{INTRODUCCIÓN}

A lo largo del siglo XIX y primera mitad del XX se realizaron una serie de estudios de geografía médica. Las geografías o topografías médicas presentan un interés indudable para los historiadores de la Medicina, Geografía, Sociología y Ecología. Asimismo, su consulta ofrece informaciones valiosas para los estudiosos de la vida local, en sus vertientes demográfica, agraria, social y urbana. Estas geografías médicas se definían como el estudio de las relaciones existentes entre el medio físico y social y el estado de la salud de la población.

Fecha de recepción: 14 de Noviembre de 2013. Fecha de aceptación: 25 de Noviembre de 2014.

1 Departamento de Geografía, Ciudad Universitaria Cantoblanco, 28049 Madrid, francisco.feo@uam.es 
Como ha señalado Luis Urteaga, «a lo largo del ochocientos, se produce en España una expansión progresiva de los estudios de geografía médica, que alcanza su punto culminante en la octava década de la centuria. En esta expansión juegan un papel decisivo diversas corporaciones científicas, especialmente las Sociedades de Higiene y las Reales Academias de Medicina, que elaboran planes y ofrecen pautas para la realización de estos trabajos y mantienen un sistema de recompensas para sus autores. En este sentido, podemos referirnos al paradigma de las topografías médicas como un programa de investigación institucionalizado» (URTEAGA, 1980, pp. 37-38). El propio Luis Urteaga señala la existencia de más de doscientas topografías médicas entre 1800 y 1940 y considera que la lista dista de ser exhaustiva. Si tenemos en cuenta algunas anteriores y posteriores y otras que permanecieron inéditas, como la de Caso aquí analizada, tal vez se podría elevar la cifra en otro centenar.

En la paulatina crisis de las geografías médicas va a jugar un papel decisivo que el enfoque higienista entra en claro retroceso a fines del siglo XIX siendo reemplazado paulatinamente por el bacteriológico, innovador y apoyado en el prestigio del triunfo de las vacunaciones (OLIVERA, 1986, pp. 349).

Como ha señalado Ana Olivera, el contenido de las geografías-topografías médicas distaba muy poco de los estudios geográficos regionales clásicos (OLIVERA, 1993, pp. 9), con un enfoque medioambiental físico básico aunque no falte tampoco preocupación por las enfermedades asociadas a los procesos de urbanización e industrialización, a los nuevos problemas de limpieza de las calles, alcantarillado, abastecimiento de agua y alimentos, problemas sanitarios de los cementerios, alcoholismo de los obreros, etc., especialmente en los del centro de Asturias por actividades mineras e industriales, contaminación, reumatismo, bronquitis crónica, etc., (FEO PARRONDO, 1996, pp. 14).

Entre las geografías médicas asturianas está la inédita sobre Caso, escrita entre 1941 y 1945, que con el título «Topografía médica del término municipal de Caso» y el lema «El bien del cielo nos vino» se envió para el Premio Roel en 1945-1946 a la Real Academia Nacional de Medicina de Madrid, en cuya biblioteca se conserva (2-4 Pasillo 38-4) con 64 cuartillas a máquina, repartidas en diez apartados, que sirvieron de base a esta publicación. Al no ser una de las 18 geografías médicas asturianas que obtuvieron el «Premio Roel» (OJEDA, 2006) permaneció inédita hasta ahora.

\section{DESCRIPCIÓN DEL MUNICIPIO}

El anónimo médico inicia su estudio sobre Caso, dividido en diez apartados, describiendo su llegada a dicho municipio y, concretamente, a Tanes de Caso, localidad para la que había sido nombrado «médico titular». Recorrió el itinerario desde Sobrescobio por una carretera «abierta a fuerza de mil trabajos» por las altas montañas y enormes masas pétreas de ambos lados, abundante vegetación, caza, pesca en el Nalón, toda clase de pastos para un variado ganado, maderas para chozas y lumbre, etc., con pocos cambios desde la colonización por los romanos de este término y del vecino de Sobrescobio. El nombre de Caso se debe al conde don Suero de Ximénez tras la reconquista. Los puertos de Tarna y San Isidro lo comunican con la provincia de León.

La superficie municipal era aproximadamente de 253`72 kilómetros cuadrados. Las 25.372 hectáreas se ocupaban desigualmente: 13.010 de bosque, 204 de secano, 5.729 de pastos, 
6.372 yermo y 57 edificadas. El censo de 1930 recopiló una población de 6.075 habitantes, unos 24 por kilómetro cuadrado. En 1945, el censo de Abastecimientos apuntó 5.349 personas de hecho (3.029 mujeres y 2.857 hombres) y 5.816 de derecho (2.839 mujeres y 2.510 hombres). Limita con los municipios de Sobrescobio, Piloña, Ponga, Aller y con la provincia de León y es atravesado por el Nalón, clave para las vegas, molinos harineros y pesca de truchas.

Eclesiásticamente pertenecía al Obispado de Oviedo y judicialmente al Partido de Laviana. Contaba con 18 escuelas (casi todas mixtas) y únicamente Abantro carecía de ella por su proximidad a Tanes. El Ayuntamiento contaba con un alcalde y ocho concejales y un presupuesto de 160.000 pesetas y en Campo de Caso había un cuartel de la Guardia Civil.

El relieve es muy desigual: a) valles bastante estrechos, algunos agrestes, por cuyo fondo circulan el Nalón y sus principales afluentes (Orlé y Caleao); b) montañas ricas en pastos; c) zona de bosques con pastos naturales que alimentan al ganado la mayor parte del año con caseríos y majadas en los puertos. El médico señala que al municipio de Caso, «su riqueza en aguas fluviales le hace muy fértil y rico en pesca. La abundancia en bosques es la delicia del cazador y la exuberancia en pastos la satisfacción del labrador y ganadero».

\section{EVOLUCIÓN HISTÓRICA}

El anónimo médico, en el capítulo segundo, señala que aunque Tolomeo achaca a los lunganes la colonización del municipio, él se inclina por la presencia de los romanos que penetraron en Asturias por el concejo de Aller, cruzaron el Nalón por Puente del Arco (Laviana) y, en Campo de Caso, crearon la casa La Torre y un puente sobre el Nalón que estaba «bastante deteriorado y peor conservado» (pp. 7). Los torreones abandonados por los romanos sirvieron para defenderse de los árabes y fueron reconstruidos por Alfonso I. En el año 858, el rey Ordoño I dona a la Iglesia ovetense las iglesias de Santa María de Sopeña (Tanes), San Salvador y San Juan.

En la Edad Media pertenecía a la merindad que abarcaba de Valdeburón hasta Siero. Para etapas posteriores casi no hay datos por ser destruido el archivo municipal durante la guerra civil, salvándose únicamente un Real privilegio otorgado por Juan II para pastar por todo el Reino con todos sus ganados y libres de pagar portazgos, peaje, barcaje, ronda, castillaje, maquilas, cueces, asadura, cucharas y tributo alguno...»(pp. 10). Fue otorgado a los vecinos y moradores de Caso para que «no se despueble y mejor se pueble, castigándose a los contraventores con la pena de diez mil maravedises» (pp. 10). Estas medidas fueron confirmadas por monarcas posteriores pero ya no son válidas por el acuerdo con el Ayuntamiento de Villaviciosa que permite que la «cabaña casina» paste los pastos de marina.

En el Archivo Municipal se conservaban antiguas ordenanzas de 1773, 1774, 1779 y 1783 y datos de personalidades de etapas anteriores (Suero de Caso, Alvar Díaz, Nuño Pérez de Caso, Francisco de Cobos, Alejo de la Soledad, José González, Xuanón de Cabañaquinta, Juan de las Traviesas Vale (varias veces diputado provincial) y su hermano Gaspar (asesinado en 1896), Patricio Sánchez de Tanes (catedrático de Derecho Civil en la Universidad de Oviedo). En 1907, el R.D. de 13 de junio, se concedió a Campo de Caso el título de Villa. Los límites actuales datan de 1827 cuando se incorpora el coto de Orlé. 


\section{MEDIO NATURAL}

Según Adaro, seguido por el anónimo médico de Caso, el terreno siluriano, la caliza carbonera, el hullero inferior y el aluvial son los representantes geológicos de Caso y de la mayor parte de Asturias. El siluriano es el más numeroso incluyendo cuarcita, pórfido y algunas variedades de pizarra. La caliza carbonera, similar a la de Aller, no es muy rica pero hay algunas explotaciones de capas de unas 80 hectáreas que producen unas 15.000 toneladas anuales en Tanes, Abantro y Coballes.

El médico visitó el yacimiento de cobre en Caón, tras subir cimas pedregosas, con explotaciones rudimentarias (hornos, escombreras) que producen un 3\% de tirita; el de cinabrio en Bezanes, etc., constatando un rendimiento escaso por su difícil acceso. Escasa era la explotación en las vegas por la dedicación a trigo y prados.

El accidentado relieve de la cordillera hace que se busque una explotación más bien ganadera por ricos pastos y de caza por abundantes cotos.

El Nalón, que nace en el puerto de Tarna, es el eje hidrográfico y cuenta con los afluentes Ablanosa, San Salvador, Caleao y Valdetanes por la izquierda y el Orlé por la derecha, que generan valles estrechos con laderas pronunciadas que, no obstante, poseen ricas vegas. Son abundantes las aguas superficiales, manantiales, fuentes, arroyuelos, etc., utilizadas para consumo doméstico, riegos y producción de energía para los molinos harineros. Aún sin contar con análisis bacteriológicos, el médico de Caso las califica de bastante aceptables bacteriológicamente por no conocerse ningún caso de infección hídrica, siendo agradables aunque algunas algo frías incluso en verano.

Las montañas están cubiertas de niebla y los prados siempre verdes, pero el cielo casi siempre cubierto por lo que no alcanza la incomparable belleza del cielo de Castilla según el anónimo médico. Unos dos tercios anuales, el cielo permanece encapotado con nubes y nieblas y unos ochenta días se mantiene despejado. Llueve unos cien días al año predominando de octubre a primavera y siendo acompañado algunos días de intensas heladas y alguna nevada que cubre en invierno las cimas de los montes lo que no impide que algunos años cubra también los valles como en 1945 cuando alcanzó en Tanes un metro de altura pese a ser el pueblo más bajo del municipio. Las lluvias, frecuentes a lo largo del año, rondaban los 700-800 milímetros anuales, aunque se reducían notablemente en verano lo que aprovechaban los campesinos para curar la hierba para el consumo animal en invierno.

El viento dominante es del Nordeste, frecuente y moderado. A finales de octubre y primeros de noviembre domina el viento del Sur, precursor de la invernada y conocido como «viento de las castañas» porque hace que caigan y facilita su recogida al tirar las maduras. El viento del suroeste es el que aporta más lluvias, el del Norte agua, nieve y granizo y el del Noroeste orbayu.

La temperatura media es benigna, entre 9 y 11 grados. El anónimo médico señala que, personalmente, llegó a observar una mínima de $-10^{\circ}$ y una máxima de $35^{\circ}$ a la sombra. En general, el clima es templado, pero un poco menos por la proximidad de los puertos de montaña. Casi un siglo antes, Pascual Madoz señala que el municipio tenía un terreno escabroso y un clima bastante sano que disponía de todos los vientos (MADOZ, 1847, t. 4, pp. 70). En 1982, Oliva Armayor señala que el municipio de Caso tenía un relieve 
accidentado con acusadas pendientes, un clima húmedo y bastante frío en invierno con temperaturas entre -1 y -4 grados y llegando a 17 grados en verano.

Armayor señala que hay suficientes lluvias todo el año y, sobre todo, de noviembre a mayo y nevadas de diciembre a febrero o marzo (ARMAYOR, 1982, pp. 149). Las precipitaciones son 1.200-1.500 milímetros en el centro y norte provincial y 1.700 en el sur, límite con la provincia de León (ARMAYOR, 1982, pp. 149).

Para el médico de Caso, «con un clima de estas características, la vegetación tiene que ser variada y exuberante, espontánea en su casi totalidad» (pp. 22) y crecen plantas por doquier. El bosque cuenta con hayas, robles, castaños, etc., y abundantes helechos que se utilizaban para hacer la cama o mullido del ganado en las cuadras. La relación de especies vegetales era muy variada, mezclándose frecuentemente las naturales y las aprovechadas por el campesinado para alimentación propia y del ganado, como combustible, adorno, etc.: abeto, ciprés, enebro, sabina, zarzaparrilla, maíz, trigo, escanda, cebada, ajo, cebolla, puerro, tulipán, margaritas, higuera, espinaca, acelga, remolacha, patata, pimiento, tomate, menta, romero, olmo, abedul, sauce, álamo, chopo, castaño, avellano, nogal, haya, encina, roble, vid, tilo, nabos, repollo, haba, rosas, fresas, zarzamoras, manzano, peral, ciruelo, albaricoque, melocotón, piesco, cerezo, zanahoria, perejil, anís, apio, eucalipto, menta, tomillo, orégano, fresno, calabazón, manzanilla, lechuga, escarola, etc. En los valles abundaban los árboles frutales y en los montes altos helechos, castaños, robles, hayas, abedules, etc. Cuatro décadas después, Oliva Armayor señala que los robles, hayas, castaños y abedules predominan en los montes y que los pastos ocupaban buena parte de las zonas comunales.

Los animales dañinos fueron retrocediendo por la expansión humana pero aún pervivían culebras, víboras, garrapata, arañas, cucarachas, hormigas, piojos, moscas, mosquitos, pulgas, polillas, abejas, avispas, ranas, sapos, salamandra, culebras, víboras, lagartijas, codorniz, perdiz, tordo, cuervo, gorrión, lechuza, búho, gavilán, milano, jabalí, corzo, ratón, liebre, ardilla, topo, oso, lobo, zorro, lince, murciélago, etc. En 1982, se realizaba caza mayor (osos, lobos, rebecos y corzos), menor (urogallo, faisán y chocha) y se pescaban truchas (unos 1.500 kilos al año) (ARMAYOR, 1982, pp. 152).

\section{POBLAMIENTO}

El médico de Caso, siguiendo a Spengler, señala que la casa es la expresión más pura de la raza y de la Geografía, adaptándose a la topografía y raza y ocupaciones de cada zona y, concretamente en Caso, en laderas y valles formando pueblos y caseríos.

La evolución lenta de las casinas ha mejorado las habitaciones y tras la guerra civil, Regiones Devastadas ha reconstruido pueblos como Tarna, Pendones y La Foz y la población indiana remozó muchas antiguas viviendas y «las viviendas viejas que aún se conservan, son hechas a base de piedra mal unida con argamasa, sin revoco, con cocina de llar sin salidas de humos, con una techumbre interior para colgar las carnes que se ahúman. En el piso superior, habitaciones grandes de una sola pieza, a veces durmiendo en promiscuidad, con galería al exterior. El piso de la cocina era de tierra apisonada. Pero estas casas, por suerte, se ven pocas» (pp. 31). En 1982, las casas son de piedra y ladrillo con techos a dos vertientes y bastante inclinados por las abundantes lluvias y nieves. Tienen dos plantas y 
un desván para guardar las cosechas. Como combustible se usa leña, preferentemente de haya y roble. Los suelos son de baldosa y madera (ARMAYOR, 1982, pp. 152).

La vivienda está bien construida pero sin reglas de orientación: cocina en el bajo y otra mayor ocupada sobre todo en invierno; almacén en el bajo de apeos de labranza, habitaciones de dormir con galerías al exterior (unas con cristales y otras sin ellos), careciendo casi todas de agua corriente, armarios, etc. Si disponen mayoritariamente de maseras para amasar el pan, utensilios de cocina (potes, peroles), arca de nogal o castaño para guardar alimentos aunque tienden a ser sustituidos por hórreos o paneras que almacenan cereales. En un edificio adjunto lo habitual es una cuadra con un desván encima donde guardan hierba seca para el consumo invernal del ganado.

El anónimo médico señala que «de los edificios públicos, salvo las iglesias y de estas pocas, no hay nada digno de mención» (pp. 33). Algunas casas particulares y chalets de indianos fueron destruidos al final de la guerra civil. La iglesia de Santa María la Real de Tanes data del siglo X, fue reconstruida en 1717 y reparada en 1882. La ermita de la Magdalena, filial de la de Tanes, se construyó en 1640-1641. Antigua y bien conservada pervivía la iglesia de Caleao.

Las escuelas eran de tipo corriente aunque algunas se adaptaban más a las modernas concepciones higiénico-pedagógicas como ocurría con las de Tarna. Los puentes fueron destruidos durante la guerra civil y posteriormente reconstruidos todos.

Los pueblos agrupan viviendas básicamente en la hondonada del valle o en una ladera (por ejemplo, Tanes) y el resto suelen ser viviendas separadas y/o agrupadas de dos a seis (Valderosa, Ablanedo, Recastañera, Campiello, etc.). Los pueblos carecían de calles y los caminos se veían afectados por aguas superficiales y residuales, estiércol, basuras de todas clases, etc., mostrándose más limpias las pequeñas agrupaciones de casas y las aisladas. Un servicio básico era la luz eléctrica, existente en todos los pueblos salvo la Felguerina.

\section{MODO DE VIDA Y ALIMENTACIÓN}

El anónimo médico señala que el habitante de esta zona es astur, noble, fuerte, aguerrido y trabajador, de altura media, cabellos castaños o negros, bien proporcionados, musculosos y nada obesos. En pueblos como Govezanes y Bueres guardan tradiciones pero ya no se veía el traje regional. Alguna anciana continuaba con labores textiles en el hogar pero estaban siendo sustituidas por un telar en Govezanes donde se hacían telas para vestido y sábanas. Conservaban cantos típicos (vaqueiradas) y el bable aunque cada vez era más sustituido por el castellano aunque se mantuviesen vocablos locales tradicionales.

Al comienzo de la primavera, el ganado es trasladado a los puertos produciéndose una aglomeración de personas y vacas en casas exclusivamente para guarecerse con camas frecuentemente solo de helecho y con alimentación a base de leche y borona, aunque la mayor parte de la leche ordeñada se bajaba todos los días al pueblo. Esta situación se repite con pequeños matices en la mayor parte de las zonas rurales asturianas en las que había trashumancias todos los años hacia las sierras en verano y hacia los valles en invierno, generando frecuentes problemas como ocurrió históricamente con los vaqueiros de alzada en la zona occidental (FEO PARRONDO, 1986). 
El tiempo de ocio lo ocupaban, especialmente en invierno, en el juego de bolos, que seguía conservando su tradicional pujanza y aún pervive hoy en día, casi siete décadas después. Además de las fiestas dominicales, había las tradicionales de cada pueblo, siendo la más importante la del Cristo de Tanes. Asimismo, tenían notable importancia las ferias de ganado de octubre, noviembre y mayo en Campo de Caso y los mercados los martes, desde septiembre, en Caleao y los miércoles de todo el año en Campo de Caso.

La alimentación de los habitantes del municipio de Caso era variada, predominando el consumo de patatas y harina de maíz. La mayor parte del pan era de escanda y de maíz en forma de boroña (sola, con chorizo y/o tocino, tortas). Las patatas se cocían con judías, fréjoles, guisantes, repollos, berzas y acelgas y eran, frecuentemente, casi el único alimento de las clases pobres. Suplemento de estos cocidos eran las carnes de cerdo todo el año y, en menor medida, las de ternera y oveja. El consumo de pescado se centraba en las truchas y, raramente, en sardinas del mar.

Junto con las patatas, la leche era fundamental al consumirse sola o en derivados como manteca y queso, con los «afoga el pito» y «picón» con mucha aceptación. El café se consume a diario mientras vino y sidra natural se demanda básicamente en bodas, fiestas, etc. La comida del mediodía era el cocido o pote asturiano en el que se mezclaban judías, patatas, berzas y derivados del cerdo. Estos últimos (porcino) se convertían en segundo plato y, frecuentemente, en merienda. La cena se basaba generalmente en patatas asadas al horno, harinas, alguna vez castañas, acompañándolas siempre de leche. En romerías y bodas, este menú se variaba y se ampliaban los platos de carne, situación que también se daba en las matanzas invernales de cerdos, en Carnaval con $<$ frixuelos $>$, en Navidad con $<$ casadiellas $>$ y en Pascua con los <bollos a los ahijados $>$.

\section{ECONOMÍA}

El médico de Caso dedica el capítulo octavo al análisis de la economía del municipio en el siguiente orden: bosques, ganadería, agricultura, pesca, caza, agroindustrias, comercio y transporte.

Los bosques ocupaban 13.010 hectáreas con numerosos ejemplares de robles, castaños y hayas, predominando estas últimas. Era una enorme riqueza que se explotaba en beneficio de las minas y se usaba para la extracción del tanino de los castaños viejos, que estaban esquilmando los bosques. El haya era utilizada principalmente por los madreñeros, que también utilizaban otras maderas, especialmente en Soto, Bezanes, La Foz, Pendones y Tarna, donde todos los hombres eran madreñeros y luego explotaban las madreñas y conseguían los primeros premios en los concursos celebrados en Oviedo.

Los pastos se encontraban en los valles y laderas formando los prados de riego y secano respectivamente, pero la mayor parte están en los altos, de un modo natural. Los prados se abonaban con estiércol del ganado y se aprovechaban en verde y se segaban en verano para que secasen y se guardaba en <tenadas> y <balagares> para alimentar el ganado en invierno. En 1982, Oliva Armayor reincide al señalar que hay mejores condiciones para la ganadería que para la agricultura por altura y, sobre todo, por pendientes (ARMAYOR, 1982, pp. 150). Las fincas regadas se destinan a pasto y «la ganadería está representada por la vacuna, criándose con especialidad, hasta hace 
pocos años, la raza <casina>. Este famoso ganado se considera como el más apropiado para recorrer los pastos difíciles de los breñales y tierras en extremo ásperas del concejo, y sus vacas proporcionan una leche de la mejor calidad. De ahí la importancia y la fama del queso casín. Hay también ganado lanar, cabrío y de cerda, y en mucho menor número caballar, asnal y mular. Se crían gallinas y conejos y también hay colmenas» (ARMAYOR, 1982, pp. 150).

El ganado vacuno era la principal riqueza del concejo: contaba con 9.739 cabezas de vacuno, 238 de caballar, 15 de mular, 180 de asnal, 1936 de lanar, 999 de cabrío y 885 de porcino. La producción de leche era de unos 3.942.000 litros anuales. Este ganado vacuno era de la «raza casina», la típica asturiana de la montaña, pequeña, poco comedora pese a lo cual tenía abundante carne, mucha leche, era mansa y muy resistente para los trabajos rurales como trasladar estiércol, labrar, etc. Parte de la leche y manteca era consumida por los ganaderos, pero la mayoría se exportaba en manteca y quesos elaborados domésticamente. La producción cárnica se vendía mayoritariamente a las carnicerías. Existían también vacas importadas (holandesa y suiza) que se habían cruzado con las casinas tradicionales, raza en la que predominaban los sementales.

Un siglo antes del escrito del médico de Caso, Pascual Madoz ya señaló, en 1847, que el Ayuntamiento de Caso «está en posesión y disfrute antiquísimo de que sus ganados pasten durante el invierno, en las riberas del mar cercanas a Villaviciosa (MADOZ, 1847, pp. 70). El propio Madoz señala la existencia en Caso de ganado vacuno, de cerda, lanar y cabrío (MADOZ, 1847, pp. 70).

La vaca asturiana de montaña es conocida como «casina» lo que incita a considerarla históricamente como la tradicional de Caso, municipio con muy alta tradición de una cabaña bovina que durante siglos aprovechó los pastizales de las zonas altas del término. Su producción de leche con amplia materia grasa es la base del queso Casín desde la Edad Media hasta hoy. Unas 8.000 hectáreas de pastizales de montaña hay actualmente para alimentar vacuno de carne y leche de la raza casina (vaca asturiana de montaña).

Casi dos décadas después del manuscrito que sirve de base a este estudio, Manuel Ferrer Regales señalaba que, desde la Edad Media, los ganaderos del Alto Nalón descendían con parte del ganado a las zonas próximas a la costa en invierno, arrendando pastos en las «Mariñas de Villaviciosa» (FERRER REGALES, 1963, pp. 8), mientras el resto quedaba estabulado y adaptándose a una naturaleza hosca con ovejas churras y vacas casinas. El propio Manuel Ferrer señala que «los concejos de Campo de Caso, Ponga y Aller son sin duda los que demuestran una mayor fidelidad a la vieja tradición ganadera, y los que más cuidan la pureza de la raza» (FERRER REGALÉS, 1963, pp. 76).

En ganado equino predominaban caballos y yeguas de la raza percheron, muy apreciadas en el municipio y en los limítrofes. Existía una parada caballar del Estado.

El ganado porcino, a diferencia de otros municipios, no formaba manadas sino que en cada casa solía haber uno para matar, para hacer el San Martín y autoabastecerse de carne todo el año. Del resto de la ganadería se aprovechaba, sobre todo en verano, las pieles y la carne.

Los cultivos más extensos eran la patata y el maíz para el consumo humano. Menor superficie se destinaba a la escanda y al trigo, sobre todo en terrenos pobres. También se cultivaban judías, cebollas, habas y berzas para el consumo humano y remolacha y nabos 
para el ganado. Entre los frutos destacaba el avellano, la castaña, la manzana y la nuez, que se exportaban, sobre todo la avellana y manzana. La castaña, sin gran trabajo (solamente recogerla), era un alimento habitual en invierno, sobre todo entre la población pobre.

A mediados del siglo XIX, Pascual Madoz apunta que, en el municipio, se cultivaban escanda, centeno, maíz, patatas, habas, hortalizas y frutas, las cuales suelen perderse muchos años por los hielos de primavera (MADOZ, 1847, pp. 70). En 1982, Oliva Armayor apunta que los valles del Nalón, Caleao y Orlé tienen tierras arcillosas y poco profundas en las que se cultivan maíz, patatas, nabos, fabes, guisantes y hortalizas, cebollas, ajos y algunas zanahorias (ARMAYOR, 1982, pp. 150). La propia Armayor señala que «la propiedad está muy repartida y las parcelas suelen tener una extensión aproximada de 10 áreas, son de formas diversas y están cercadas por sebes o muros de piedra. Aún se usa el arado romano, así como también el carro del mismo origen. La tracción para el cultivo de las tierras es animal, y para ella se utiliza el ganado vacuno» (ARMAYOR, 1982, pp. 150). Actualmente, la agricultura es básicamente para autoconsumo familiar.

Según el anónimo médico, «la riqueza en truchas es importantísima, viéndose muchos pescadores, ya que en esta zona se conserva el Nalón completamente puro de residuos carboneros» (pp.43), por lo que acudían a pescar aficionados de municipios limítrofes y de otros bastante cercanos como Oviedo, Gijón y Langreo. Anguilas apenas había. En 1982, Armayor señaló que las truchas han sido claves hasta que se contamina con carbón.

En la fauna, «el jabalí sigue haciendo acto de presencia por los sembrados, se le persigue, siendo su carne muy apreciada y aprovechada como la del cerdo» (pp. 44). Había algún oso pero no se le veía hace tiempo. El lobo era abundante sobre todo en los puertos donde el ganado doméstico pasa muchos meses. Sin embargo, «su captura o muerte es premiada, siendo exhibidas las piezas por los pueblos y recibiendo los cazadores donativos» (pp.44), situación que parece increíble en las últimas décadas.

La protección dada por la Sociedad de Caza y Pesca ha hecho que los dos ejemplares dignos del cazador no se hayan extinguido: la gamuza o rebecu y el corzo. Se encuentra algún venado. Había también perdiz, codorniz, paloma torcaz, faisán del bosque, liebres. Las martas, comadrejas y zorros eran escasos pero de piel apreciada.

Las principales industrias eran la manteca y el queso. Había muchos artesanos que se dedicaban a hacer madreñas para calzado, dedicándose casi exclusivamente los habitantes de los pueblos de Soto, Bezanes, La Foz, Pendones y Tarna a «tan lucrativo negocio, habiendo obtenido en los concursos de Oviedo varios premios» (pp. 44). En 1982, Oliva Armayor señala, como industrias del concejo, el queso y las almadreñas y, la explotación del espato fluor en Caleao y La Felguerina (ARMAYOR, 1982, pp. 155-156).

El comercio era reducido y se dedicaba a transaciones de ganado productor de leche, premiado en los diversos concursos de ganado en la provincia. La economía, básicamente de autosubsistencia, queda clara cuando el anónimo médico señala que «existen algunas tiendas dedicadas a la venta de artículos de uso, vestido y alimenticios» (pp. 45).

La carretera principal era la de Oviedo a Tarna que seguía a León y pasaba por los pueblos de Tanes, Coballes, Campo de Caso, Veneros, Soto, Bezanes, La Foz y Tarna. Desde Coballes partía un ramal a Caleao de unos seis kilómetros. Asimismo, desde Coballes y, por la margen derecha del Nalón otra llegaba a Orlé, cerca de Prieres, Govezanes 
y Bueres, enlazando en esta última localidad con la que va al concejo de Infiesto, al igual que la procedente de Tanes y Abantro. El ferrocarril más cercano pasaba por la estación más cercana, la de Rioseco a siete kilómetros de Tanes.

Como ha apuntado Oliva Armayor, en las décadas finales del XIX se empiezan a crear y mejorar carreteras pero a un ritmo lento por el accidentado relieve. El Puerto de Tarna se habilitó para el tráfico rodado en julio de 1935 y se vio afectado por la guerra civil que arrasó Tarna y parte de Campo de Caso.

\section{CAMBIOS DEMOGRÁFICOS Y ASPECTOS SANITARIOS}

Desde mediados del siglo XIX, se aprecia en Asturias «una marcada tendencia al despoblamiento de sus áreas rurales, en especial en la montaña media y alta» (PÉREZ GONZÁLEZ, 1983, pp. 235). Aunque la población asturiana creció de 627.069 habitantes en 1900 a 888.149 en 1950 (PÉREZ GONZÁLEZ, 1983, pp. 239), Caso, como otros municipios montañosos del interior, ha figurado en el siglo $\mathrm{XX}$ entre los que han tenido una menor densidad de población. Entre 10 y 24 habitantes $/ \mathrm{km}^{2}$ en 1900 y menos de 10 en 1981 (PÉREZ GONZÁLEZ, 1983, pp. 242-243).

El municipio de Caso ha tenido 5.412 habitantes en 1900, 5529 en 1910, 5547 en 1920, 5416 en 1930, 5303 en 1940, 4866 en 1950, 4105 en 1960, 2520 en 1981, 2121 en 1991 y 1962 en 2001, cifras que muestran un descenso muy considerable a lo largo del siglo XX: casi un 62\% de habitantes menos en 2001 que en 1900.

Entre 1900 y 1960, la densidad demográfica en Caso se reduce casi la cuarta parte pasando de 16 a 12`2 habitantes/km2 (ARMAYOR, 1982, pp. 152) y se reduce a la mitad su aportación al total demográfico asturiano. 0`8\% en 1900 y 0`4\% en 1960 (ARMAYOR, 1982, pp. 152). Según Oliva Armayor, en 1982, «la mayor parte de los pueblos de este municipio dan la impresión de ir en camino de su extinción. El movimiento migratorio no cesa; la juventud se va marchando al extranjero; la brújula de las masas migratorias, que antes apuntaba hacia países americanos, especialmente a la Argentina, ha girado hacia los países centroeuropeos» (ARMAYOR, 1982, pp. 155). Como consecuencia hay pocos matrimonios, envejecimiento, descenso demográfico, cierre de escuelas rurales aisladas y éxodo rural, etc. (ARMAYOR, 1982, pp. 155). Desde mediados del siglo XX ha habido un amplio éxodo rural que se ha traducido en un descenso de la actividad agrícola e incremento de la ganadera y forestal.

El anónimo médico de Caso dispuso solamente de datos del «periodo 1939-1945 ya que de los archivos de años anteriores no quedó nada» (pp. 46). Entre enero de 1939 y septiembre de 1945 nacieron, en el término de Caso, 687 niños (353 varones y 334 niñas) con ligeras oscilaciones anuales (mínimo de 78 en 1945 y máximo de 107 en 1941 y 1944). De ellos, 8 nacieron muertos o fallecieron el primer día y 79 antes de cumplir un año.

En el mismo periodo se celebraron 283 matrimonios de los que 263 fueron entre solteros, 10 entre viudo y soltera, 7 entre soltero y viuda y 3 entre viudo y viuda. El máximo número de matrimonios fue en 1941 con 50 y el mínimo en 1939 con 28, diferencia justificable por el fin de la guerra civil. Predominaron los matrimonios de 20 a 35 años en ambos sexos, siendo significativos también los matrimonios de mujeres de menos de veinte años y de entre 36 y 40 en los hombres. 
Entre enero de 1939 y septiembre de 1945 fallecieron en Caso 283 hombres y 308 mujeres, mayoritariamente solteros en ambos sexos (119 y 124 respectivamente) y con descenso anual de las cifras de muertos: de 51 a 29 hombres y de 53 a 32 mujeres en dichos años. En este periodo, la mayor mortalidad fue en marzo de 1943 con 17 fallecidos y las mínimas en junio de 1939, único mes sin ningún muerto, y junio de 1941 y mayo de 1944 con un fallecido cada uno.

Siguiendo el Nomenclator, el médico de Caso hace una relación minuciosa de las causas de mortalidad por 107 enfermedades distintas que, en la mayoría de los casos no llegaban a causar cada una ni diez fallecimientos. Las principales causas de mortalidad fueron las pulmonares, bronquitis y neumonías, algunas gripes, vejez, hemorragia cerebral, etc. La mayor mortalidad se daba en los meses de enero, marzo y noviembre, pero no con un predominio muy grande con los demás meses. Las infecciones tifo-paratifo no causaron mucha mortalidad por la bondad de las aguas y se debieron a los alimentos aunque «a pesar de las enormes trasgresiones alimenticias, la mortalidad por enfermedades de la nutrición en los niños no es muy elevada si se compara con las del aparato respiratorio» (pp. 56). Por su parte, «la difteria dio algunos casos hasta tanto que se hizo la vacunación obligatoria» (pp. 56).

Las enfermedades más abundantes eran las del aparato respiratorio, seguidas de las de carácter vascular, sobre todo las de origen reumático. Las dos epidemias de sarampión y coqueluche que hubo desde que el médico llegó a Caso tuvieron escasas complicaciones y mortalidad. Hubo, asimismo, dos epidemias de tétanos casi simultáneos pese a que eran desconocidas por completo en la región.

La tuberculosis pulmonar afectó a gran número de personas, la meningitis especialmente a los jóvenes, la difteria en expansión obligó a la vacunación, la encefalitis a los niños, la mortalidad por carcinoma o tumores fue bastante considerable, el reumatismo (generalmente el de tipo crónico) se vio favorecido por el clima húmedo siendo muy frecuente el de tipo crónico que propició lesiones valvulares, artritis, bocio, raquitismo, histerismo, mielitis, esclerosis, etc.

El clima húmedo propiciaba numerosas afecciones del aparato respiratorio y un elevado porcentaje de mortalidad entre los niños, frecuentemente con neumonías. Los trastornos nutritivos afectaban a los lactantes y, sobre todo, a adultos que comían alimentos fríos y bebían mucha agua frecuentemente. Asimismo, eran frecuentes las gastritis por comidas picantes. Frecuentes eran también las hernias y los afectados se resistían a operaciones urgentes pese a ser muy necesarias. Por el contrario, pese a la carencia de educación prenatal, la gestación y los partos se desenvuelven de modo normal.

Para el médico de Caso, como para la mayoría de los que hicieron otras geografías médicas similares, la higiene de casa y alrededores, la carencia de ventilación, la promiscuidad, convivencia con animales y proximidad del estiércol, etc., juegan un papel decisivo en la expansión de la tuberculosis y bronquitis, especialmente en los niños que carecen de baños y realizan comidas poco adecuadas para la edad. Asimismo, la casi totalidad de las viviendas carecían de poca higiene, ventilación y desinfección y sus dueños no hacían caso a las sugerencias de los médicos y aunque el de Caso reconoció que difundió las vacunaciones antivariólica y la antidiftérica, revisó a mujeres en su gestación, etc., consideró imprescindible la mejora en la higiene, déficit apuntado por la práctica totalidad de médicos españoles que escribieron geografías médicas similares sobre todo el territorio español. 


\section{BIBLIOGRAFÍA}

ARMAYOR, O. (1982): «Caso» en Gran Enciclopedia Asturiana, Gijón, Silverio Cañada, t. 4, pp. 148-160.

CABAL, M. (1978): Un siglo de medicina asturiana, Oviedo, Summa, 590 págs.

FEO PARRONDO, F. (1986): Los vaqueiros de alzada. Estudio geográfico de un grupo marginado, Oviedo, Caja de Ahorros de Asturias, 164 págs.

FEO PARRONDO, F. (1996): Geografías médicas de Tineo de 1886, 1907 y 1913, Oviedo, Principado de Asturias, 176 págs.

FEO PARRONDO, F. (1997): «Geografía médica del concejo asturiano de Carreño (1919)», Polígonos, 7, pp. 9-28.

FEO PARRONDO, F. (2001): «Geografía médica del Valle de Arán (1913)», Lurralde, 28, pp. 69-84.

FEO PARRONDO, F. (2002): «Geografía médica de Aguaviva (Teruel) en 1913», en Aportaciones geográficas en memoria del prof. L. Miguel Yetano Ruiz, Zaragoza, Universidad, 546 págs., cfr. pp. 195-201.

FEO PARRONDO, F. (2004): «Geografía médica de Santa Cruz de Tenerife (1909)», Vegueta. Anuario de la Facultad de Geografía e Historia, 8, pp. 151-168.

FEO PARRONDO, F. (2008): «Geografía médica del concejo de Llanes (1940)», Nimbus, 21-22, pp. 93-108.

FEO PARRONDO, F. (2009): «Geografía médica de Reocín (1909)», Lurralde, 32, pp. 227-254.

FEO PARRONDO, F. (2011): «Geografía médica y epidemias en Villarta de los Montes (Badajoz) (1904-1912)», Nimbus, 27-28, pp. 5-24.

FEO PARRONDO, F. (2012): «Geografía médica de Pravia (Asturias) (1940)», Nimbus, 29-30, pp. 233-242.

FERRER REGALÉS, M. (1963): La ganadería bovina en la Región Asturcántabra (Oviedo y Santander), Oviedo, Diputación de Oviedo e Instituto de Estudios Asturianos, 114 págs.

HAGGETT, P. (2000): The geographical structure of epidemics, Oxford, University Press, 150 págs.

MADOZ, P. (1847): «Caso» en Diccionario Geográfico-Estadístico de España y sus posesiones de ultramar, Madrid, La Ilustración, t. 6, pp. 70.

OJEDA, G. (2006): Biografía contemporánea de Asturias. Condiciones de vida en la región en torno a la primera mitad del siglo XX, Oviedo, Cajastur, 568 págs.

OLIVERA, A. (1986): «Nuevos planteamientos de la Geografía médica” en GARCÍA BALLESTEROS, A. (Coord): Teoría y práctica de la Geografía, Madrid, Alhambra, 372 págs., cfr. pp. 348-360.

OLIVERA, A. (1993): Geografía de la salud, Madrid, Síntesis, 160 págs.

PÉREZ GONZÁLEZ, R. (1983): «La población de Asturias» en Geografía de Asturias, Geografía Humana III, Salinas, Ayalga, t. 4, pp. 234-269.

PÉREZ MOREDA, V. (1980): La crisis de la mortalidad en la España interior, siglos $X V I-X X$, Madrid, Siglo XXI, 526 págs.

URTEAGA, L. (1980): «Miseria, miasmas y microbios. Las topografías médicas y el estudio del medio ambiente en el siglo XIX», Geocrítica, 29, 50 págs. 
UTANDA MORENO, L. (1997a): «Topografía médica de Aranjuez (1923)», Estudios Geográficos, 229, pp. 711-723.

UTANDA MORENO, L. (1997b): «Geografía médica de Aranjuez (1940)», Anales de Geografía de la Universidad Complutense, 17, pp. 239-255. 
